\title{
Exercise intolerance in pulmonary arterial hypertension: insight into central and peripheral pathophysiological mechanisms
}

\author{
Simon Malenfant $\mathbb{1}^{1,2}$, Marius Lebret ${ }^{1,2}$, Émilie Breton-Gagnon ${ }^{1,2}$, François Potus ${ }^{1}$, Roxane Paulin ${ }^{1,2}$, \\ Sébastien Bonnet ${ }^{1,2}$ and Steeve Provencher ${ }^{1,2}$
}

${ }^{1}$ Pulmonary Hypertension and Vascular Biology Research Group, Quebec Heart and Lung Institute Research Center, Quebec City, Canada. ${ }^{2}$ Dept of Medicine, Faculty of Medicine, Université Laval, Quebec City, Canada.

Corresponding author: Simon Malenfant (simon.malenfant.2@ulaval.ca)

\begin{abstract}
Shareable abstract (@ERSpublications)
Cardiorespiratory, cerebrovascular and skeletal muscle (impaired skeletal muscle morphology, convective $\mathrm{O}_{2}$ transport, capillarity and metabolism) dysfunctions contribute symbiotically to reduce exercise capacity in patients with $\mathrm{PAH}$ https://bit.ly/3hOQxJB
\end{abstract}

Cite this article as: Malenfant S, Lebret M, Breton-Gagnon É, et al. Exercise intolerance in pulmonary arterial hypertension: insight into central and peripheral pathophysiological mechanisms. Eur Respir Rev 2021; 30: 200284 [DOI: 10.1183/16000617.0284-2020].

Copyright OERS 2021.

This article is open access and distributed under the terms of the Creative Commons Attribution Non-Commercial Licence 4.0.

Received: 29 Aug 2020 Accepted: 8 Dec 2020

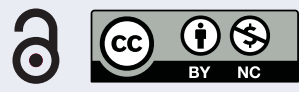

\section{Abstract}

Exercise intolerance is a cardinal symptom of pulmonary arterial hypertension (PAH) and strongly impacts patients' quality of life (QoL). Although central cardiopulmonary impairments limit peak oxygen consumption $\left(V_{\mathrm{O}_{2 \text { peak }}}^{\prime}\right)$ in patients with $\mathrm{PAH}$, several peripheral abnormalities have been described over the recent decade as key determinants in exercise intolerance, including impaired skeletal muscle (SKM) morphology, convective $\mathrm{O}_{2}$ transport, capillarity and metabolism indicating that peripheral abnormalities play a greater role in limiting exercise capacity than previously thought. More recently, cerebrovascular alterations potentially contributing to exercise intolerance in patients with PAH were also documented. Currently, only cardiopulmonary rehabilitation has been shown to efficiently improve the peripheral components of exercise intolerance in patients with PAH. However, more extensive studies are needed to identify targeted interventions that would ultimately improve patients' exercise tolerance and QoL. The present review offers a broad and comprehensive analysis of the present literature about the complex mechanisms and their interactions limiting exercise in patients and suggests several gaps in knowledge that need to be addressed in the future for a better understanding of exercise intolerance in patients with PAH.

\section{Introduction}

Pulmonary hypertension (PH) is a complex clinical entity currently classified into five groups according to clinical presentation, pathological findings, pulmonary vascular haemodynamics and management characteristics [1]. The haemodynamic definition of pulmonary arterial hypertension (PAH; Group 1) was recently updated at the $6^{\text {th }}$ World Symposium on Pulmonary Hypertension (WSPH), being now characterised by the concomitant presence of mean pulmonary artery pressure (mPAP) $>20 \mathrm{mmHg}$, a pulmonary artery wedge pressure (PAWP) $\leqslant 15 \mathrm{mmHg}$ and a pulmonary vascular resistance (PVR) $\geqslant 3$ Wood units (WU) at rest [2]. Fatigue, exertional dyspnoea and a progressive reduction in daily life activities are its prime symptoms [3]. Exercise intolerance is therefore of paramount importance in limiting quality of life (QoL) in patients (figure 1). Contrary to initial beliefs, reduced exercise capacity is not solely triggered by central cardiopulmonary impairments. Several research reports published in the last decade suggest that skeletal muscle (SKM) and cerebrovascular impairments contribute in limiting exercise capacity [12-15].

This review aims to discuss measurement of exercise intolerance in patients with PAH and salient mechanisms responsible for the reduced exercise capacity in patients with $\mathrm{PAH}$, which include cardiorespiratory alterations, but also intrinsic dysfunction of peripheral and respiratory SKM morphology and function. The role of exercise training as a treatment option, as well as several gaps in the knowledge that need to be addressed to better understand exercise intolerance in those patients, is also discussed. 


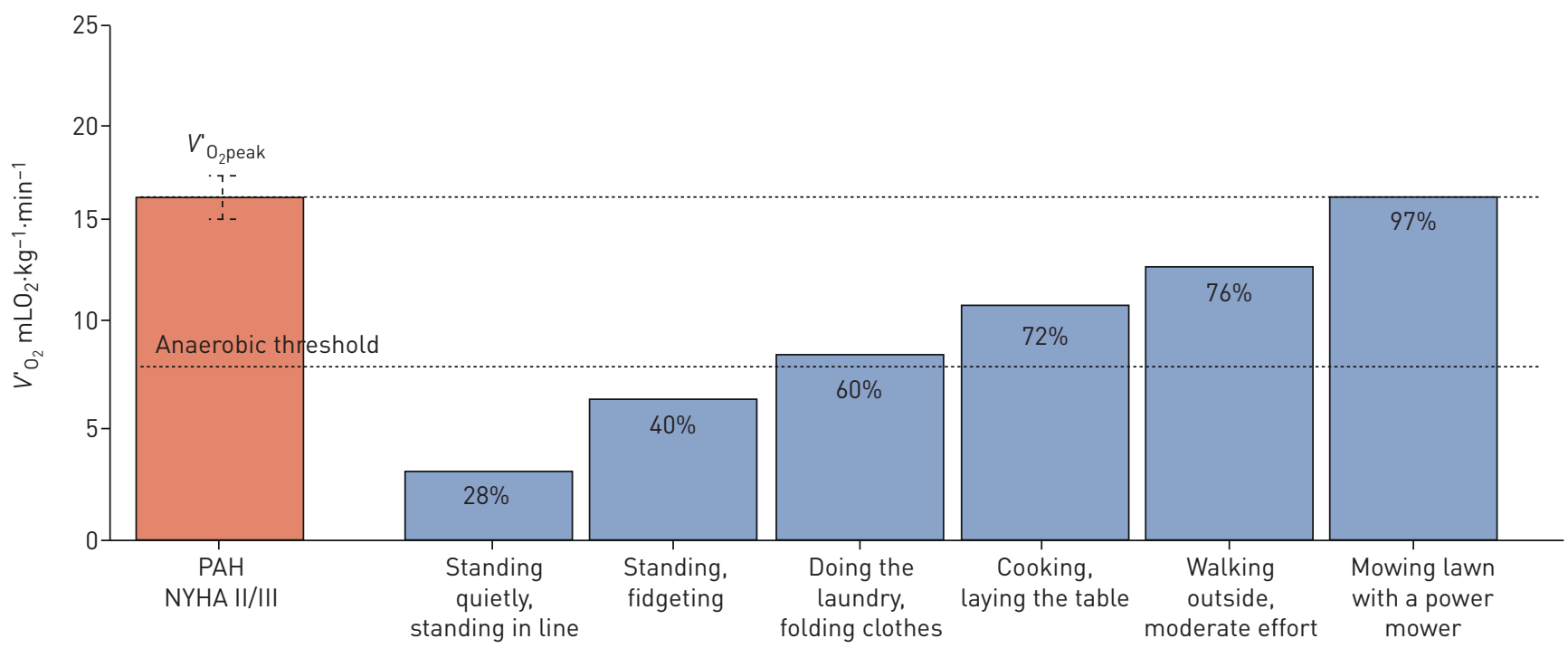

FIGURE 1 Exercise intolerance has a major impact on daily life activities. Patients rapidly reach anaerobic threshold in their daily activities, making sustained efforts difficult. Average peak oxygen uptake $\left(V^{\prime}{ }_{{ }_{2 p e a k}}\right)$ used for comparison was $16.1(1.4) \mathrm{mL} \mathrm{O}_{2} \cdot \mathrm{kg}^{-1} \cdot \mathrm{min}^{-1}$ based on six studies [4-9]. $V^{\prime} \mathrm{O}_{2}$ : standing quietly in a queue: $4.6 \mathrm{~mL} \mathrm{O} \mathrm{Kg}^{-1} \cdot \mathrm{min}^{-1}$; standing, fidgeting: $6.3 \mathrm{~mL} \mathrm{O} \cdot \mathrm{kg}^{-1} \cdot \mathrm{min}^{-1}$; doing the laundry, folding clothes: $9.8 \mathrm{~mL}$ $\mathrm{O}_{2} \cdot \mathrm{kg}^{-1} \cdot \mathrm{min}^{-1}$; cooking, laying the table: $11.6 \mathrm{~mL} \mathrm{O} \cdot \mathrm{kg}^{-1} \cdot \mathrm{min}^{-1}$; walking outside, moderate effort: $12.3 \mathrm{~mL} \mathrm{O}_{2} \cdot \mathrm{kg}^{-1} \cdot \mathrm{min}^{-1}$; $\mathrm{mowing}$ the lawn, with a power mower: $15.6 \mathrm{~mL} \mathrm{O} \cdot \mathrm{kg}^{-1} \cdot \mathrm{min}^{-1}$. Specific physical activity intensity was determined using the 2011 Compendium of Physical Activities [10]. NYHA: New York Heart Association; PAH: pulmonary arterial hypertension. Data from [11].

Measurement of exercise intolerance in patients with $\mathrm{PAH}$

Exercise testing in patients with $\mathrm{PAH}$

The most commonly used test to comprehensively assess subjects' exercise tolerance remains the cardiopulmonary exercise test (CPET) that quantifies peak oxygen consumption $\left(V_{\mathrm{O}_{2} \text { eak }}^{\prime}\right)$, carbon dioxide production $\left(V_{\mathrm{CO}_{2}}^{\prime}\right)$ and minute ventilation $\left(V_{\mathrm{E}}^{\prime}\right)$ using inspiratory and expiratory gas analysis at both rest and exercise [16]. In patients with $\mathrm{PAH}$, compared with control groups, patients are characterised by lower $V^{\prime} \mathrm{O}_{2 \text { pea }}$; higher $V_{\mathrm{E}}^{\prime} / V_{\mathrm{CO}_{2}}^{\prime}$ rate and slope; lower arterial $\mathrm{CO}_{2}$ tension and end-tidal $\mathrm{CO}_{2}$ tension $\left(P_{\mathrm{aCO}}\right.$ and $\left.P_{\mathrm{ETCO}_{2}}\right)$; lower $\mathrm{O}_{2}$ pulse (oxygen uptake over heart rate ratio $\left(V_{\mathrm{O}_{2}}^{\prime} / \mathrm{HR}\right)$ ); and lower pulse oxygen saturation $\left(S_{\mathrm{pO}_{2}}\right)$ [17-19]. Moreover, CPET has the ability to detect exercise right-to-left shunt through a patent foramen oval when patients present a sharp and sudden increase in $V^{\prime}{ }_{\mathrm{E}} / V^{\prime} \mathrm{CO}_{2}$ rate accompanied by an equally sharp and sudden decline in $P_{\mathrm{ETCO}_{2}}$ and $S_{\mathrm{pO}_{2}}$ [20]. CEPT might have a utility in patients where $\mathrm{PH}$ remains a possibility (systolic PAP $\leqslant 36 \mathrm{mmHg}$ on transthoracic echocardiography) instead of a likely diagnosis [21]. However, CPET is not sensitive enough to differentiate right ventricle (RV) from left ventricle (LV) dysfunction as only cardiac echography or invasive right heart catheterisation is able to make the differential diagnosis between these conditions. Consistently, invasive CPET with concomitant right heart catheterisation has recently gained in popularity to delineate the specific cardiorespiratory components responsible for exercise intolerance in more complex clinical settings [22, 23]. Conversely, the 6-min walk test (6MWT), which is inexpensive, safe, easy to perform, and familiar to patients and hospital staff [1], remains the most commonly applied test to assess exercise tolerance in patients with PAH on a clinical basis. Although being considered a submaximal test in healthy subjects, this test induces similar $V^{\prime}{ }_{\mathrm{O}_{2 \text { peak }}}$ responses as those observed during incremental CPET [24]. Interestingly, the 6MWT draws a parallel with daily life activity. Patients who walk an average of 5000 steps $\cdot$ day $^{-1}$ or less engage in fewer moderate-to-intense daily life physical activities (>3.0 METs (metabolic equivalent of task)) compared with their healthy counterparts [25, 26], correlating with the 6MWT results [25, 26]. Therefore, it is easy to understand how a low $V_{\mathrm{O}_{2 p e a k}}^{\prime}$ may dramatically limit patient capacity to accomplish several domestic activities (figure 1).

\section{Exercise intolerance, disease severity and prognosis}

$V_{\mathrm{O}_{2 \text { pak }}}^{\prime}, P_{\mathrm{ETCO}_{2}}, V_{\mathrm{E}}^{\prime} / V_{\mathrm{CO}_{2}}^{\prime}$ slope, as well as changes in $\mathrm{O}_{2}$ pulse, peak systolic blood pressure and $\mathrm{HR}$ during CPET were found to be related to survival in patients with PAH [27]. Nonetheless, only $V^{\prime}{ }_{\mathrm{O}_{20}}$ $\left(\leqslant 10.4 \mathrm{~mL} \cdot \mathrm{kg}^{-1} \cdot \mathrm{min}^{-1}\right)$ and systolic peak blood pressure $(\leqslant 120 \mathrm{mmHg}$ ) were independent predictors of mortality. A low 6MWT distance has also been associated with a lower survival [28]. Consistently, 
exercise capacity is now a key component of the REVEAL 2.0 [29] and European Society of Cardiology (ESC)/European Respiratory Society (ERS) [30] risk stratification tools, and current guidelines recommend measurement of exercise tolerance for decision-making [1, 14]. As such, patients with $V_{\mathrm{O}_{2 p e a k}}$ $>15 \mathrm{~mL} \cdot \mathrm{kg}^{-1} \cdot \mathrm{min}^{-1}$ (>65\% of predicted value), $V^{\prime}{ }_{\mathrm{E}} / V^{\prime} \mathrm{CO}_{2}$ slope $<36$ and a $6 \mathrm{MWT}>440 \mathrm{~m}$ have the lowest risk of mortality at 1 year [31]. While both CPET and 6MWT may be used to risk stratifying patients using the ESC/ERS risk score, CPET appears to have limited added discriminative value in prognosticating patients already evaluated by a 6MWT [32]. However, a celling effect has been described in patients with higher walking distance, in particular in those walking $>450 \mathrm{~m}$ [33, 34]. Therefore, using CPET instead of the $6 \mathrm{MWT}$ or using both tests in more fit patients may be more sensitive for risk stratification compared with 6MWT only. While patients' age, sex, height and weight influence exercise capacity independently of PAH severity, adjusting 6MWT results according to patients' characteristics has no impact on the exercise test's discriminative properties [35]. Interestingly, geographical location should be considered in risk stratification [36]. In a Brazilian cohort of 104 patients, individuals with a lower 6MWT distance had worse survival agreeing with international guidelines, but with a higher cut-off value for worse survival (250 m instead of $165 \mathrm{~m}$ ) potentially attributed to older age and sociocultural conditions [37].

Changes in exercise capacity as a marker of treatment response

Beside its discriminative property for disease severity and patients' prognosis, the 6MWT has been successfully used as a primary end-point in most randomised controlled trials in patients with PAH [38], likely because its responsiveness to clinical changes is enhanced in patients with PAH owing to its repeatability and simplicity of administration in clinical practice [4]. The minimal important difference in the 6MWT in previously untreated PAH patients is approximately $33 \mathrm{~m}$ [39]. However, improvements in 6MWT were generally $\sim 10 \%$ and $\sim 5 \%$ from baseline in monotherapy and combination therapy trials respectively [37, 40], and mean changes in 6MWT only modestly predicted the occurrence of morbidity/ mortality events [37, 40,41]. To address some of the limitations of the 6MWT as a primary outcome measure in clinical trials, researchers progressively included composite end-points reflecting time to clinical worsening [42]. It is noteworthy, however, that PAH worsening, which accounted for 55-75\% of clinical worsening defining events in most trials, has been commonly defined by signs of PAH progression together with a 10-20\% decrease in 6MWT. Conversely, CPET suffers from a lack of responsiveness following therapeutic intervention in patients with $\mathrm{PAH}$, especially in the setting of a multicentre randomised controlled trial [43-45], in keeping with previous studies documenting that peak exercise capacity is not typically responsive to intervention in COPD [46]. This is contrasting to individual changes in 6MWT following the addition of sildenafil to PAH monotherapy [38], individual CPET values [47] or a heart rate recovery $\geqslant 16 \mathrm{bpm}$ after the $6 \mathrm{MWT}$ as predictors of subsequent clinical worsening [48].

Mechanisms of exercise intolerance in patients with $\mathrm{PAH}$

Physical exercise requires the interaction of several physiological mechanisms. Both respiratory and cardiovascular systems are coupled to meet the metabolic demand of the contracting SKM. In patients with $\mathrm{PAH}$, several respiratory and cardiovascular anomalies dampen the efficacy of $\mathrm{O}_{2}$ transport to active muscles.

Impaired ventilation and blood gas during exercise

Impaired ventilation in patients with $\mathrm{PAH}$ has multiple complex origins. $\mathrm{PAH}$ is characterised by heightened ventilatory response to exercise $\left(V_{E}^{\prime} / V^{\prime} \mathrm{CO}_{2}\right.$ slope) partially attributed to pulmonary vascular remodelling leading to increased physiological dead space $\left(V_{\mathrm{D}} / V_{\mathrm{T}}\right)$ ratio and high ventilation-perfusion $\left(V^{\prime}\right)$ $Q^{\prime}$ ) heterogeneity (figure 2) $[17,49,50]$. An interesting hypothesis about the negative $V_{E}^{\prime}$ axis-intercept from the $V_{E}^{\prime} / V^{\prime} \mathrm{CO}_{2}$ slope has been raised by AGostoni et al. [51] and further reviewed by her team [52]. When passing the respiratory compensation point, the $V_{E}^{\prime} / V^{\prime} \mathrm{CO}_{2}$ slope becomes steeper and the $V_{\mathrm{E}}^{\prime}$ axis-intercept becomes negative, potentially showing a sheer increase in dead space ventilation toward the end of exercise [52]. However, the prognostic value of $V^{\prime}{ }_{E} / V^{\prime} \mathrm{CO}_{2}$ slope analysis beyond the respiratory compensation point remains to be investigated. While patients are frequently hypoxemic at rest, which even worsens during exercise [17, 53], they also have hypocapnia even in the absence of hypoxemia [52, 54]. Therefore, ventilatory inefficiency is not solely explained by increased $V_{\mathrm{D}} / V_{\mathrm{T}}$. Using the modified rebreathing protocol, increased ventilation at rest and exercise ventilatory inefficiency was recently shown as the result of increased central chemoreflex activity [5]. Consistently, FARINA et al. [55] used hypoxia and hypercapnia tests to further demonstrate that hyperventilation results from a combination of both increased dead space and central chemoreflex activity (figure 2). Taken together, ventilatory inefficiency and hypocapnia appear to be related, at least in part, to an increased central chemoreflex sensitivity that may contribute to dyspnoea in patients. 


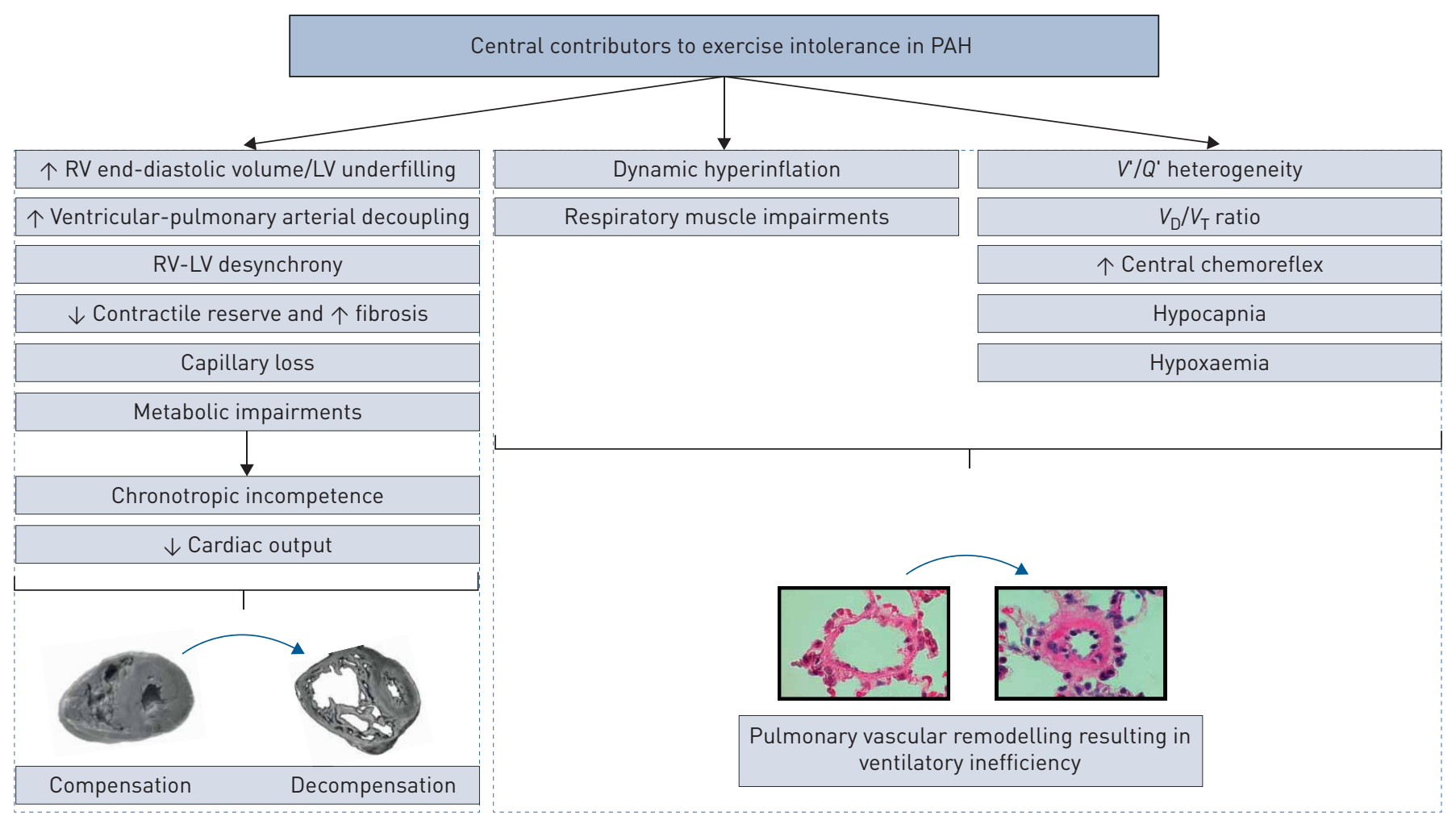

FIGURE 2 Impaired cardiac adaptation and ventilatory response to exercise in patients with pulmonary arterial hypertension (PAH). RV: right ventricle; LV: left ventricle; $V_{\mathrm{D}} / V_{\mathrm{T}}$ : dead space/tidal volume ratio; $V^{\prime} / Q^{\prime}$ : ventilation-perfusion ratio (normal ratio average 0.8).

Intriguingly, patients with PAH exhibit a more dyspnoeic pattern in relation to higher $V^{\prime}{ }_{\mathrm{E}} / V^{\prime} \mathrm{CO}_{2}$ slope and lower $\mathrm{O}_{2}$ pulse compared with patients with left heart failure (HF) at comparable exercise state [56]. Conversely, patients with HF are much more likely to present exercise oscillatory ventilation (EOV) [57, 58], a respiratory pattern expected to result from delay in information transfer between pulmonary gas exchanging capillaries and the peripheral and central chemoreceptors secondary to a fall in cardiac index [59], increased peripheral and central chemoreflex sensitivity [60] and a reduced baroreflex damping capacity [61]. Indeed, VICENZI et al. [62] found no EOV in a sample of 109 patients with PAH, whereas it was identified in $22 \%$ of the 107 patients with HF reaching $40 \%$ in patients with isolated post-capillary $\mathrm{PH}$. The differential mechanisms responsible for EOV in HF compared with PAH remains, however, elusive.

\section{Mechanical and respiratory muscle impairments}

A significant reduction in maximal inspiratory and expiratory pressure were documented in patients with PAH [63-65] and modestly correlated with exercise performance (figure 2) [63]. Human biopsy samples of diaphragm muscle fibres revealed atrophy, hypocontractility and decreased capillary density [66, 67]. Furthermore, reduced nonvolitional and isolated fibre respiratory strength were also documented in rodent PH models [68]. These abnormalities may contribute to respiratory mechanical disadvantage that leads the inability of the $V_{\mathrm{T}}$ to properly expand at the beginning of exercise to increase ventilation [69, 70]. More recently, dynamic hyperinflation, an increase in end-expiratory lung volume traditionally observed in patients with COPD, was also described in $60 \%$ of patients with $\mathrm{PAH}$ in the absence of obvious obstructive lung abnormalities or impaired inspiratory flow-generating reserve of the inspiratory muscles. Although its cause remained unknown, hyperinflation was associated with sensory consequences, including increased breathing effort and unsatisfactory inspiration [70]. Boucly et al. [69] further demonstrated that during exercise in patients with $\mathrm{PAH}$, an inflection in tidal volume $\left(V^{\prime} \mathrm{T}\right)$ response when inspiratory reserve becomes critically reduced marks a transition from increased breathing effort to unsatisfied inspiration, a far more unpleasant sensation associated with anxiety.

\section{Impaired cardiac adaptation and reserve during exercise}

In patients with $\mathrm{PAH}, \mathrm{RV}$ function prevails as an important prognostic factor. Using cardiac magnetic resonance imaging, van WOLFEREn et al. [71] determined that elevated RV end-diastolic volume index, 
low end-diastolic LV volume index (a direct consequence of LV underfilling) and low stroke volume (SV) index were strong independent predictors of mortality in patients with PAH. Compared with the LV, the RV demonstrates a heightened sensitivity to afterload changes [72], which markedly increases upon exercise in patients with PAH [73]. Moreover, according to the Frank-Sterling mechanism, when RV pre-load extends the capacity of shortening of the longitudinal circumferential oblique muscle fibres it results in insufficient myocardium contraction and low SV [74]. As such, increased pre-load forces the RV to adapt, causing hypertrophy in an attempt to maintain normal SV, a process that ultimately leads to maladaptive remodelling, followed by dilation and failure [75, 76]. Over time, RV maladaptation is characterised by progressive $\mathrm{O}_{2}$ supply-demand imbalance resulting from coronary arterial remodelling [77] and loss of capillaries [78], myocardial fibrosis [79] and metabolic remodelling from mitochondrial-based fatty acid oxidation to $\mathrm{O}_{2}$-sparing anaerobic glycolysis (figure 2) [80]. As both ventricles work in series and because of pericardial restraints [81, 82], an altered RV will also impact the LV with an important impact on its geometry, structure, and function [83] that contribute in decreasing global cardiac output (CO), especially during exercise [79, 84].

Consistently, several studies demonstrated that changes in cardiac and pulmonary haemodynamics during exertion accurately predict improvements in exercise capacity and prognosis compared with changes in resting haemodynamics [73, 85, 86], indicating that the incapacity of the RV to increase CO is an important determinant of exercise intolerance $[87,88]$. Indeed, in addition to increased afterload, impaired chronotropic response to exercise [89], ventricular-pulmonary arterial decoupling amplified with exercise [90], RV desynchrony [91], absence of RV end-systolic volume decrease with exercise [87] and depressed contractile reserve [87, 92] were demonstrated to result in this blunted increase in CO during exercise (figure 2) [56, 93]. In addition, in patients with a preserved systolic function adaptation, RV desynchrony is associated with a lower $V_{\mathrm{O} 2}^{\prime}{ }_{\text {eak }}$ [91]. Although its specific contribution to exercise intolerance in patients with $\mathrm{PAH}$ remains also understudied, significant tricuspid regurgitation may also limit increases in $\mathrm{CO}$ to meet exercise metabolic demands consistent with impaired LV pre-load [94].

\section{Impaired cerebrovascular function and oxygenation}

The regulation of cerebral blood flow (CBF) remains complex. Known determinants include systemic blood pressure, $\mathrm{CO}$, arterial blood gas content, autonomic nervous system and neurovascular coupling for meeting local cerebral metabolic demand [95]. Sustained intense exercise leads to a mild cerebral deoxygenation and metabolic perturbation in healthy individuals [96], similar to that seen in hypoxic environment such as high altitude [97]. In heathy individuals, exercise in experimental hypoxic condition leads to central fatigue that correlates with decreased cerebral oxygenation [96], suggesting that exercise tolerance could be affected by impaired cerebral oxygenation. Recent evidence suggests that lower CBF and oxygenation may be limiting exercise capacity in patients with HF [98-100]. Lower CO and higher ventilatory response to exercise are also hypothesised to be involved in lower cerebral perfusion and oxygenation [98, 101]. In addition, impaired CBF regulatory mechanisms are impaired as well in HF and as a possible consequence, blood pressure modulations is buffered less efficiently and may fail to meet increased metabolic demands with exercise [102-104]. Recently, we [5] and others [105, 106] demonstrated that patients with PAH also have lower CBF and impaired regulatory mechanisms, altering the buffering of blood pressure changes and potentially explaining why patients with $\mathrm{PAH}$ are more prone to syncope after Valsalva-induced decreases in blood pressure [107]. At exercise, cerebral oxygenation was also markedly impaired during incremental $[5,106]$ and endurance exercise [108], tightly correlating with the exercise capacity of patients with $\mathrm{PAH}$ [5]. Interestingly, oxygen supplementation significantly enhanced cerebral oxygenation, maximal workload and endurance time during exercise, attesting of its probable relevance for exercise tolerance in patients with PAH [109].

\section{Peripheral skeletal muscle limitation to exercise in patients with $P A H$} Morphological abnormalities

Several morphological and functional impairments have been observed in peripheral SKM (figure 3), including reduction in both volitional $[6,7,63,110]$ and nonvolitional strength [6, 7]; and endurance [66]. The force-generating capacity of muscle fibres are typically proportional to their cross-sectional area (CSA). MANDERS et al. [111] reported that the maximal force of isolated permeabilised fast-twitch quadriceps fibres, normalised to fibre CSA, was significantly lower in patients with PAH. This diminished maximal force was related to a decreased active stiffness in fast-twitch muscle fibres, suggesting a reduction in the number of available active actin-myosin cross-bridge from a loss of the major contractile protein myosin. In addition, numerous signalling abnormalities associated with SKM dysfunction have been described in recent years. These include suppression of signalling pathways responsible for SKM hypertrophic response, elevation of signalling pathways responsible for atrophic response and engagement of ubiquitin-proteasome-mediated muscle proteolysis signalling [112-115]. A recent plasma metabolomics 


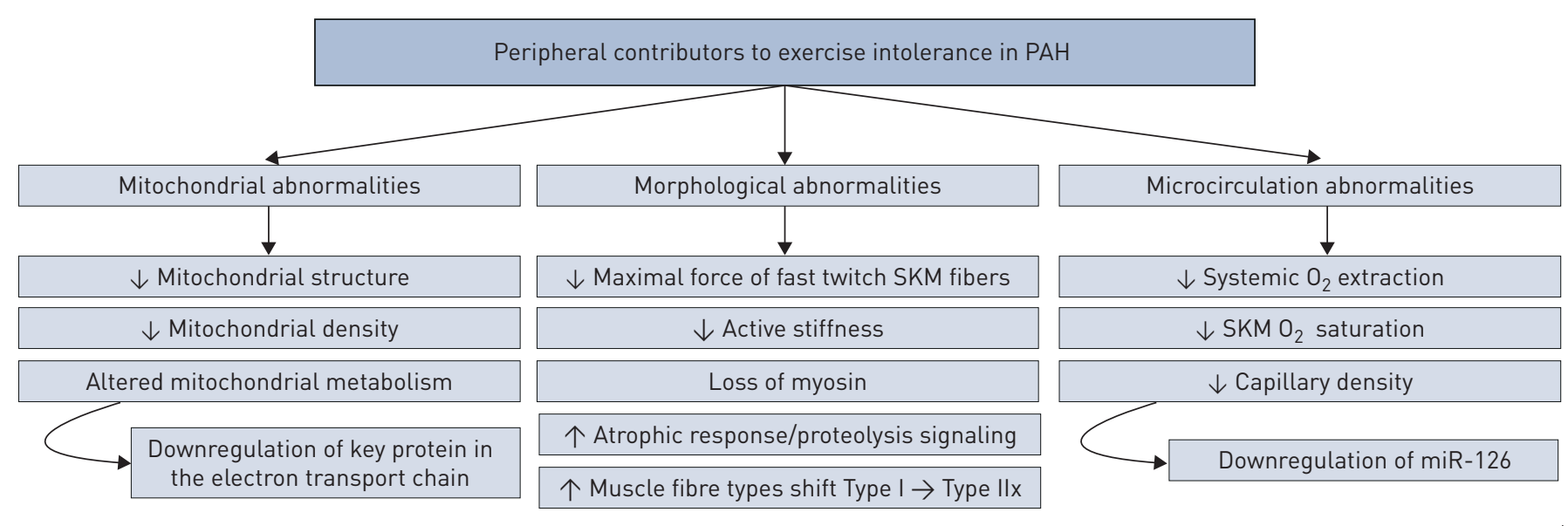

ᄂ

Functional impairments

$\downarrow$ SKM endurance

$\downarrow$ SKM strength

FIGURE 3 Skeletal muscle (SKM) determinants of exercise intolerance in patients with pulmonary arterial hypertension (PAH).

profile also found that patients with PAH are characterised by increased levels of circulating modified fatty oxidation residues [116]. These metabolites could act as pro-inflammatory modulators, ultimately promoting muscle catabolism. Interestingly, pharmacological blockade of excessive fatty oxidation was shown to protect human myotubes and protect peripheral muscle against atrophy in cancer cachexia models in vivo [117]. Pre-clinical data also indicates a potential role for nutrition, as supplementing mice with an anti-inflammatory diet resulted in decreased RV hypertrophy, fibrosis and inflammation while preventing SKM atrophy [118]. It is noteworthy, however, that despite molecular abnormalities promoting atrophy being documented in patients with $\mathrm{PAH}$, most studies in human $\mathrm{PAH}$ documented no changes in whole muscle $[6,7,63,66]$ or fast-twitch fibre CSA [111].

SKM typology and oxidative capacity are also affected in patients with PAH (figure 3). A significant shift in muscle fibre types from oxidative type I toward more glycolytic type IIx has been documented in most studies involving human $\mathrm{PH}[6,112,119]$ and experimental $\mathrm{PH}$ [114] although this was not uniformly observed [7, 66]. Consistently, a significant reduction in SKM oxidative capacity [6, 119, 120] were repeatedly documented in muscle samples from both humans and rodents with PAH.

\section{Skeletal muscle microcirculation abnormalities}

Under normal physiologic circumstances, skeletal and respiratory muscles account for around $40 \%$ of the body mass and are responsible for up to $30 \%$ of resting $\mathrm{O}_{2}$ consumption [121]. During exercise, the proportion of the CO diverted to respiratory [122-124] and skeletal [125] muscles increase markedly, a situation where the $\mathrm{O}_{2}$ cost of breathing approaches $10-15 \%$ of the total $V^{\prime} \mathrm{O}_{2 \mathrm{Max}}$ in healthy subjects [126]. TolLE et al. [127] first documented profound impairments in systemic $\mathrm{O}_{2}$ extraction at the end of maximal exercise in patients with PAH compared with patients with preserved and reduced ejection fraction HF (HFpEF and HFrEF respectively). These results were substantiated by evidence from our group where patients with $\mathrm{PAH}$ exhibited a decrease in muscle $\mathrm{O}_{2}$ saturation and increased deoxyHb-Mb during both normoxic and hyperoxic submaximal exercise at the same workload despite near-normal systemic oxygen delivery [7] and compatible with reduced total systemic $\mathrm{O}_{2}$ extraction and $\mathrm{O}_{2}$ utilisation from exercising muscles [128]. These impairments were related to a lower capillary density rather than impaired systemic blood flow and oxygen delivery, and correlated with $V_{\mathrm{O}_{2 \text { peak }}}^{\prime}$, suggesting that impaired convective and diffusive muscle $\mathrm{O}_{2}$ supply contributes to exercise intolerance [7], but also contribute to reduced daily physical activity (figures 3 and 4) [129]. SKM capillary rarefaction was shown to be mediated, at least in part, by a downregulation of the microRNA (miR)-126 resulting in the downregulation of the downstream effectors of the vascular endothelial growth factor pathway (figure 3) [66]. This phenomenon was unique to patients with PAH and not found in equally exercise intolerant patients with COPD [66]. Interestingly, the restoration of miR-126 levels in monocrotaline-induced PH rats resulted in improved SKM perfusion 


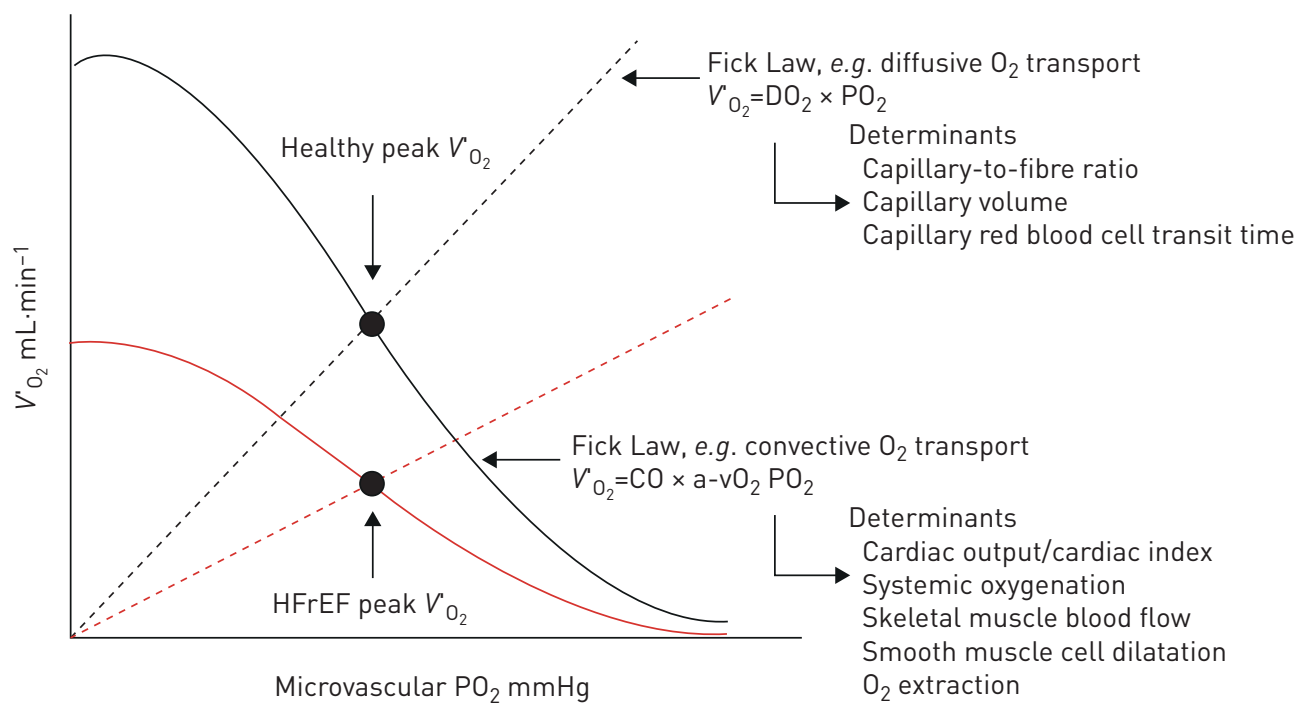

FIGURE 4 The Wagner diagram. Oxygen uptake is plotted as a function of microvascular oxygen pressure. Black line: diffusive (Fick law) and convective (Fick principal) components that interact to determine peak oxygen uptake $\left(V^{\prime}{ }_{\mathrm{O}_{2 \text { peak }}}\right)$. The Fick principle line is not straight because it directly represents the haemoglobin dissociation curve (greater haemoglobin $\mathrm{O}_{2}$ affinity), resulting in a lower venous $\mathrm{O}_{2}$ partial pressure [130]. The slope of the straight line (Fick law) is determined by the diffusing capacity of the muscles [130]. Red line: in patients with heart failure, a left-shifted haemoglobin dissociation curve (greater haemoglobin $\mathrm{O}_{2}$ affinity), resulting in a lower venous $\mathrm{O}_{2}$ partial pressure, and a lower slope of the Fick law line results in earlier bisection of both diffusive and convective components and reduced $\mathrm{V}^{\prime} \mathrm{O}_{2 \text { peak }}$. a- $\mathrm{VO}_{2}$ : arterio-venous difference; $\mathrm{DO}_{2}$ : oxygen delivery; $\mathrm{HFrEF}$ : heart failure with reduced ejection fraction; $\mathrm{PO}_{2}$ : partial pressure of oxygen; $\mathrm{CO}$ : cardiac output.

and treadmill distance while artificial diminution of miR-126 levels in the SKM of healthy rats has the opposite effect [66], demonstrating a relatively maintained SKM plasticity in patients with PAH.

Diminished $\mathrm{O}_{2}$ transport might also result from endothelial dysfunction that characterises PAH and markedly influences peripheral endothelium-dependent flow-mediated vascular tone [46, 131, 132]. For example, slow-twitch muscle fibre vessels are more prone to endothelin-1 (ET-1)-induced vasoconstriction than fast-twitch muscle fibre vessels, influencing endogenous vascular tone in the forearm and leg of healthy subjects [132-135]. Similarly, detrained slow-twitch fibre vessels have less eNOS expression than fast-twitch fibres [136, 137], and the combined inhibition of NO and prostaglandins markedly reduces SKM blood flow $[138,139]$. Consistently, endothelin receptor antagonists were recently shown to improve angiogenesis of Sugen/hypoxia-induced PH [78, 140]. Interestingly, reduced capillary density was partly restored by ET-1 receptor antagonist macitentan within the lungs, RV and muscles of treated rats [140], raising questions on whether the pulmonary and systemic vascular defects could be connected by similar molecular mechanisms.

\section{Skeletal muscle mitochondrial function abnormalities}

The reduction in SKM oxidative capacity previously described suggests significant mitochondrial impairment in patients with PAH [112]. This hypothesis was further supported by the whole proteomic profile of human PAH SKMs realised by our group, showing significant downregulation of key proteins involved in the electron transport chain complex I, III, ATP synthase complex, citric acid cycle, mitochondrial metabolism, ADP/ATP translocase and the fatty acid metabolism [119]. Bioinformatics analyses from Gene Ontology enrichment confirmed a significant downregulation of protein complex involved in oxidative metabolism and mitochondrial integrity, whereas electronic microscopy and enzymatic activity confirmed abnormal mitochondrial crest structure and density [119]. Note that similar mitochondrial dysfunction also occurs in PAH RV [141], but ENACHE et al. [142] reported that SKM mitochondrial dysfunction precedes RV impairment in an experimental model of PAH supporting the hypothesis that SKM defect is an early characteristic of the disease. However, no studies have explored the impact of disease severity on mitochondrial function. One potential avenue to explore may be if peripheral 
muscle inflammation impact muscle mitochondrial function in a similar fashion than in pulmonary artery smooth muscle cells [143]. Contrary to previous studies, Sithamparanathan et al. [144] showed a prolonged phosphocreatine recovery time and abnormal SKM pH suggesting an altered $\mathrm{O}_{2}$ delivery over an altered $\mathrm{O}_{2}$ utilisation as the main contributor to exercise intolerance, but normal mitochondrial function and subunit protein abundance in the electron transport chain. However, the absence of paired control subjects, the lack of measurements of the ATP cost of contraction or the limited details regarding the exercise done to measure phosphocreatine recovery time preclude confident conclusions to be made from that study. Interestingly, McCullough et al. [145] demonstrated plasticity in mitochondrial function after endurance exercise training in Sugen/hypoxia PAH rat model, especially for mitochondrial complex I and III.

Exercise as an adjunct treatment strategy

For several years, exercise was contraindicated for patients with PAH who were considered at risk for exercise-induced RV failure, syncope or sudden death [146]. In line with earlier concerns, НАNDоко et al. [146] demonstrated that exercise training could be detrimental in monocrotaline rats with severe and progressive $\mathrm{PH}$, but resulted in improved exercise capacity, pulmonary haemodynamics and RV capillarisation in their counterparts with stable PH. In humans, Mereles et al. [147] conducted the first prospective randomised trial evaluating the effect of exercise and respiratory training in severe symptomatic patients under optimised medical therapy. The first 3 weeks of training were in-hospital while the remaining weeks of the program were done at home, supervised by phone. After 15 weeks of training, the 6MWT distance decreased in control group $(-15 \pm 54 \mathrm{~m})$ while it increased in the training group (+96 $\pm 61 \mathrm{~m}$ ) with a mean difference of $111 \mathrm{~m}(95 \%$ CI 65 to $139 \mathrm{~m}, \mathrm{p}<0.001)$, combined with a significant improvement in QoL [147]. Since then, similar beneficial exercise training effects were demonstrated in patients with PAH [148, 149], patients with PAH associated with connective tissue disease [150] and patients with congenital heart disease [151], as well as patients with chronic thromboembolic PH [152]. Inspiratory muscles training as an add-on therapy to cardiopulmonary rehabilitation has also been associated with a decreased sensation of dyspnoea [153, 154]. A meta-analysis of 16 studies confirmed that exercise was likely associated with significant improvement in exercise tolerance and potentially better pulmonary haemodynamics in patients with PAH [155]. Safety was also assessed. Adverse events were more frequent in outpatients, including episodes of dizziness, pre-syncope, syncope, palpitations, arrhythmia, fatigue, hypotension or $\mathrm{O}_{2}$ desaturation being observed in $4.7 \%$ of patients with overall protocol dropout $<1 \%[14,155]$.

The mechanisms for improvements in exercise capacity are still lacking. EHLKEN et al. [156] investigates the effects of exercise training on cardiopulmonary function and RV haemodynamics using the same training planning as in Mereles et al. [147]. $V_{\mathrm{O}_{2 p a a k}}^{\prime}$ was significantly improved in the training group (+3.1 $\pm 2.7 \mathrm{~mL} \mathrm{O}{ }_{2} \cdot \mathrm{min}^{-1} \cdot \mathrm{Kg}^{-1}$ versus $-0.2 \pm 2.3 \mathrm{~mL} \mathrm{O} \mathrm{O}_{2} \cdot \mathrm{min}^{-1} \cdot \mathrm{Kg}^{-1}$ ), consisting of a $25 \%$ increase for the training group versus $1 \%$ in controls [156]. 6MWT, QoL and resting pulmonary haemodynamics measured invasively were also significantly improved with exercise. The specific mechanisms of pulmonary haemodynamic improvements with exercise remain to be investigated, but the current hypothesis implicates a training-induced reduction in pro-inflammatory cytokines and an antioxidant effect [157].

However, a disproportionate improvement in $V^{\prime}{ }_{\mathrm{O}_{\text {peak }}}$ compared with resting pulmonary haemodynamics after exercise (25\% versus 15\%) suggests that peripheral mechanisms may also contribute to exercise intolerance. In support of this argument, the loss of capillary density has been closely coupled with SKM fatigue independently of arterial blood flow, leading to long-term exercise intolerance if left untreated following capillary occlusion in rats' hindlimbs [158]. Therefore, muscle dysfunction, but primarily capillary loss in patients with $\mathrm{PAH}$, if left untreated, may curtail exercise rehabilitation improvements. Partially supporting this idea, GonzALEz-SAIz et al. [8] focused on peak muscle power during bench presses and leg presses in a randomised clinical trial over a 8-week period and found a significant improvement in SKM power and strength, increased $V_{\mathrm{O}_{2} \text { peak }}^{\prime}(+17 \%$ from baseline) and a better QoL and daily physical activity in patients with $\mathrm{PAH}$. This last study demonstrates that significant results may be achieved over a relatively short period of time.

\section{Gaps in knowledge}

Pulmonary pressure, flow and distensibility during exercise

Moderate exercise induces a linear increase in CO and a concomitant minor decrease in PVR secondary to dilation of compliant pulmonary capillaries and, although controversial, the potential recruitment of additional capillaries in the upper lobes. Altogether, this results in relatively mild increases in mPAP [159, 160]. Before 2008, mPAP >30 mmHg upon exercise was defined as exercise $\mathrm{PH}(\mathrm{ePH})$, whatever exercise intensity, type and position of exercise [161]. However, a systematic review documented that close to $50 \%$ 
of healthy individuals over 50 years of age reached such levels upon mild-to-moderate exercise without any symptoms [162], so that this criterion was no longer considered as reflecting an abnormal response to exercise.

More recently, NAEIJE et al. [163] proposed that the limit-of-normal for the mPAP-CO relationship ranges between 0.5 and $3.0 \mathrm{mmHg} \cdot \mathrm{L}^{-1} \cdot \mathrm{min}^{-1}$, corresponding to a maximal total pulmonary resistance (TPR) of 3 WU during exercise. By testing this proposition, HeRve et al. [164] confirmed that a TPR of $\geqslant 3$ WU and $\mathrm{mPAP} \geqslant 30 \mathrm{mmHg}$ reached at maximal exercise delineated controls from patients with early pulmonary vascular disease or left heart disease (LHD) with a sensitivity of 0.99 and a specificity of 0.95 amongst 169 individuals with resting mPAP $\leqslant 20 \mathrm{mmHg}$. Most recently, Ho et al. [165] prospectively analysed a total of 714 patients with dyspnoea on exertion and preserved ejection fraction investigated with invasive CPET using a slightly different approach. Over a median follow-up period of 3.7 years, individuals with a $\mathrm{mPAP} / \mathrm{CO}$ slope $>3 \mathrm{mmHg} \cdot \mathrm{L}^{-1} \cdot \mathrm{min}^{-1}$ during exercise had a 2 -fold increase risk of cardiovascular hospitalisation or all-cause mortality including in the subgroup of patients with a resting mPAP $\leqslant 20 \mathrm{mmHg}$ [165]. Nonetheless, the proposed cut-off values (mPAP $\geqslant 30 \mathrm{mmHg}$, TPR $\geqslant 3 \mathrm{WU}$ or $\mathrm{mPAP} / \mathrm{CO}$ slope $>3 \mathrm{mmHg} \cdot \mathrm{L}^{-1} \cdot \mathrm{min}^{-1}$ during exercise) alone are insufficient to distinguish LHD from early pulmonary vascular disease. Moreover, the appropriate interpretation of age-dependency of these measures together with the limited data about the clinical relevance of ePH prevented its re-introduction in the hemodynamic definition of $\mathrm{PH}[2]$.

Interestingly, the introduction of ambrisentan in patients with so-called ePH (resting mPAP: $18 \mathrm{mmHg}$; peak exercise mPAP: $36 \mathrm{mmHg}$ ) resulted in a significant decline in peak exercise mPAP $(-5.2 \pm 5.6 \mathrm{mmHg})$ and PVR $(-0.9 \pm 0.7 \mathrm{WU})$ together with a significant increase in CO $\left(+2.3 \pm 1.4 \mathrm{~L} \cdot \mathrm{min}^{-1}\right)$ and pulmonary vascular compliance $\left(+0.8 \pm 1.4 \mathrm{~mL} \cdot \mathrm{mmHg}^{-1}\right)$ suggesting that $\mathrm{ePH}$ may respond to current $\mathrm{PAH}$-specific therapies [166]. Intriguingly, these improvements were not associated with statistically significant increases in $V^{\prime}{ }_{\mathrm{O}_{2 \text { peak }}}$. The mechanisms responsible for this disconnection remains elusive. However, how this increased blood flow is distributed during exercise or following treatment may be important: if patients are expected to benefit from favourable pulmonary vasodilation (in ventilated areas), these effects may be offset by less favourable vasodilation resulting in $V^{\prime} / Q^{\prime}$ mismatch or increased shunt, as previously observed in patients with COPD treated with calcium channel blockers [167] or prostacyclin [168].

Also of interest, the assessment of pulmonary vascular distensibility during exercise may eventually help discriminating early pulmonary vascular disease during exercise prior to symptomatic exercise dyspnoea [169]. Pulmonary vascular distensibility predicts aerobic capacity in healthy individuals. Athletes with the highest maximal aerobic capacity have the greatest distensibility, increase in capillary blood volume and lowest PVR at maximal exercise [170]. In recent cohort studies, decreased distensibility was not only primarily observed in patients with PAH when compared with healthy controls, HFrEF and HFpEF, but was also associated with right ventricle-pulmonary artery (RV-PA) uncoupling and decreased $V_{\mathrm{O}_{2 p e a k}}[171,172]$. The clinical relevance of impaired pulmonary vascular distensibility in term of its ability to distinguish LHD from PAH with confidence remains, however, unknown [173]. Hopefully, an ERS Clinical Research Collaboration called the pulmonary haemodynamics during exercise - research network (PEX-NET) will provide answers regarding prognostic relevance of ePH in terms of mortality/lung transplantation (primary end-point) and hospitalisation, development of $\mathrm{PH}$ at rest, or initiation of targeted $\mathrm{PAH}$ medication (secondary end-points) [174].

\section{Convective and diffusive $\mathrm{O}_{2}$ transport}

Reduced $V^{\prime} \mathrm{O}_{2}$ may result from either convective or diffusive $\mathrm{O}_{2}$ transport limitations [130]. Convective elements include CO, systemic oxygenation, SKM blood flow, leg smooth muscle cells vasodilation and $\mathrm{O}_{2}$ extraction; while diffusive elements include capillary-to-fibre ratio, capillary density and capillary red blood cells transit time in the active muscle (figure 4) [130, 175, 176]. The specific contributions of convective versus diffusive limitations in $\mathrm{O}_{2}$ transport in patients with $\mathrm{PAH}$ remain largely unknown. As we previously mentioned, the proportion of the CO diverted to skeletal muscles increases markedly during exercise [125]. Similarly, blood flow to the respiratory muscles increases substantially during maximal exercise [122-124], a situation where the $\mathrm{O}_{2}$ cost of breathing in normal subjects approaches $10-15 \%$ of the total $V_{\mathrm{O}_{2 \max }}^{\prime}$ [126]. In healthy subjects, this “competition" for redistribution of CO is only relevant during strenuous exercise [177]. However, in COPD and HF, increased flow distribution to the respiratory muscles at the expense of the lower limb muscles is observed during submaximal exercise [178, 179], contributing to excessive SKM fatigue, effort perception and decreased exercise capacity [180, 181]. Such "vascular steal" by the respiratory muscles may also occur in patients with PAH since respiratory workload is markedly increased at rest and during exercise secondary to mild obstructive and/or restrictive defects 
[53, 182], hyperventilation and increased dead space ventilation [17, 53, 54], resulting in major interference with oxygen delivery to the working muscles.

Oxygen delivery at the microcirculation level may also be involved. Intriguingly, the incapacity to increase $V^{\prime} \mathrm{O}_{2 \text { peak }}$ following the addition of ambrisentan in patients with ePH [166] previously mentioned may have resulted from the combination of increased systemic $\mathrm{O}_{2}$ delivery with a decreased systemic $\mathrm{O}_{2}$ extraction [183]. Those two physiological mechanisms may explain this finding, in accordance to the Wagner diagram (figure 4). First, a lower SKM capillary-to-fibre ratio and oxidative enzyme capacity [9, 119] combined with a lower capillary density [66] may result in perfusion and oxidative metabolism mismatch following drug-induced increases in limb blood flow resulting in decreased systemic $\mathrm{O}_{2}$ extraction. Secondly, muscle atrophy and excitation-contraction impairment [112] combined with intrinsic muscle mitochondrial dysfunction [119] may also contribute to impaired systemic $\mathrm{O}_{2}$ extraction. These studies all argue in favour of the combined contributions of convective and diffusive $\mathrm{O}_{2}$ defects in patients with $\mathrm{PAH}$ leading impaired $V^{\prime}{ }_{\mathrm{O}_{2 \text { peak }}}$.

Furthermore, endothelial dysfunction has also been demonstrated in the peripheral circulation of patients with PAH (reviewed by Nickel et al. [12]) and may also limit $V^{\prime} \mathrm{O}_{2}$. During exercise, in healthy subjects, regional blood supply progressively shifts from other organs to exercising muscles, and within muscle toward more oxidative fibres. Interestingly, CANo et al. [184] determined that heterogeneity in SKM may have a greater impact on limiting $V^{\prime} \mathrm{O}_{2}$ than $V^{\prime} / Q^{\prime}$ heterogeneity in the lungs, especially when mitochondrial metabolic capacity is slightly higher than the potential to deliver $\mathrm{O}_{2}$ to the mitochondria (e.g. lower capillary density hence diffusive component).

In HFrEF, using small muscle mass to prevent exceeding the cardiac pumping capacity that necessitates enhancing sympathetic vasoconstriction within the exercising muscle, Esposito et al. [185] first demonstrated that $V^{\prime} \mathrm{O}_{2}$ limitation comes from both convective and diffusive $\mathrm{O}_{2}$ transport defects in SKM, whereas isolated lower leg cardiorespiratory rehabilitation restored muscle exercise capacity resulting from increased capillary-to-fibre ratio and oxidative capacity in the trained leg muscles [186, 187]. In HFpEF, the $\mathrm{O}_{2}$ pathway with the largest impact on exercise capacity was located in the periphery as well, more precisely related to the $\mathrm{O}_{2}$ diffusion capacity and utilisation within exercising muscles [11, 188, 189]. Similar results were observed in COPD [190]. Therefore, altered convective and diffusive components of $\mathrm{O}_{2}$ transport remain to be explored in patients with PAH and may explain at least in part the limited increases in peak improvements $V^{\prime} \mathrm{O}_{2}$ with current therapies.

\section{Contribution of skeletal muscle ergoreflex to exercise intolerance}

Within SKM, the ergoreflex consists of contraction-induced mechanical and chemical stimuli that activate thinly myelinated (group III) and unmyelinated (Group IV) afferent nerve fibres projecting via the dorsal horn of the spinal cord to various sites within the central nervous system [191]. In HFrEF, muscle ergoreflex activity has been assessed using post-exercise regional circulatory occlusion. Its overactivation was associated with abnormally elevated ventilatory response to exercise, attenuation of baroreflex and peripheral chemoreceptor overactivation, suggesting an interplay between enhanced sympathetic overdrive and exercise intolerance [192]. Furthermore, muscle ergoreflex overactivity was observed in both noncachexic and cachexic patients with a strong association between muscle reflex overactivity and muscle cachexia [193]. Spinal anaesthesia has been used to partially block group III/IV muscle sensory afferents and resulted in reduced exercise ventilatory response to exercise [194], decreased peripheral fatigue sensing leading to more profound muscle fatigue $[195,196]$ and a higher energy cost of muscle contraction [197] in both healthy individuals and athletes. In COPD, the use of spinal anaesthesia also reduced ventilatory response to exercise, hyperinflation and dyspnoea, resulting in prolonged endurance capacity [198]. Therefore, it remains plausible that ventilatory response to exercise, dyspnoea and enhanced muscle sympathetic overdrive are also at interplay in patients with PAH, contributing to exercise intolerance.

\section{Conclusion}

Cardiorespiratory, cerebrovascular and SKM systems are affected in patients with PAH and translate into clinical symptoms such as exertional dyspnoea, fatigue, weakness and RV failure symptoms. Exercise testing is not only an objective measure of the patient's functional status, but also represents an important adjunct to prognostications and the assessment of response to therapy. In addition to currently approved vasodilatory medications, cardiopulmonary rehabilitation also represents a key strategy to alleviate exercise intolerance in patients with PAH. However, further studies are needed to: 1) fully determine the mechanisms and relevance of ePH; 2) elucidate the role of convective and diffusive $\mathrm{O}_{2}$ transport in limiting $V_{\mathrm{O}_{2 \text { peak }}}^{\prime}$; and 3) elucidate the role of muscle ergoreflex in exercise intolerance in patients. 
Provenance: Submitted article, peer reviewed

Conflict of interest: None declared.

\section{References}

1 Galie N, Humbert M, Vachiery JL, et al. 2015 ESC/ERS guidelines for the diagnosis and treatment of pulmonary hypertension: The Joint Task Force for the Diagnosis and Treatment of Pulmonary Hypertension of the European Society of Cardiology (ESC) and the European Respiratory Society (ERS): Endorsed by: Association for European Paediatric and Congenital Cardiology (AEPC), International Society for Heart and Lung Transplantation (ISHLT). Eur Respir J 2015; 46: 903-975.

2 Simonneau G, Montani D, Celermajer DS, et al. Haemodynamic definitions and updated clinical classification of pulmonary hypertension. Eur Respir J 2019; 53: 1801913.

3 Frost A, Badesch D, Gibbs JSR, et al. Diagnosis of pulmonary hypertension. Eur Respir J 2019; 53: 1801904.

4 Mainguy V, Malenfant S, Neyron AS, et al. Repeatability and responsiveness of exercise tests in pulmonary arterial hypertension. Eur Respir J 2013; 42: 425-434.

5 Malenfant S, Brassard $\mathrm{P}$, Paquette $\mathrm{M}$, et al. Compromised cerebrovascular regulation and cerebral oxygenation in pulmonary arterial hypertension. J Am Heart Assoc 2017; 6: e006126.

6 Mainguy V, Maltais F, Saey D, et al. Peripheral muscle dysfunction in idiopathic pulmonary arterial hypertension. Thorax 2010; 65: 113-117.

7 Malenfant S, Potus F, Mainguy V, et al. Impaired skeletal muscle oxygenation and exercise tolerance in pulmonary hypertension. Med Sci Sports Exerc 2015; 47: 2273-2282.

8 Gonzalez-Saiz L, Fiuza-Luces C, Sanchis-Gomar F, et al. Benefits of skeletal-muscle exercise training in pulmonary arterial hypertension: the WHOLEi+12 trial. Int J Cardiol 2017; 231: 277-283.

9 de Man FS, Handoko ML, Groepenhoff $\mathrm{H}$, et al. Effects of exercise training in patients with idiopathic pulmonary arterial hypertension. Eur Respir J 2009; 34: 669-675.

10 Ainsworth BE, Haskell WL, Herrmann SD, et al. 2011 Compendium of Physical Activities: a second update of codes and MET values. Med Sci Sports Exerc 2011; 43: 1575-1581.

11 Nayor M, Houstis NE, Namasivayam M, et al. Impaired exercise tolerance in heart failure with preserved ejection fraction: quantification of multiorgan system reserve capacity. JACC Heart Fail 2020; 8: 605-617.

12 Nickel NP, Yuan K, Dorfmuller P, et al. Beyond the lungs: systemic manifestations of pulmonary arterial hypertension. Am J Respir Crit Care Med 2020; 201: 148-157.

13 Lai YC, Provencher S, Goncharova EA. TAKling GDF-15 and skeletal muscle atrophy in pulmonary hypertension: are we there yet? Thorax 2019; 74: 103-105.

14 Grunig E, Eichstaedt C, Barbera JA, et al. ERS statement on exercise training and rehabilitation in patients with severe chronic pulmonary hypertension. Eur Respir J 2019; 53: 1800332.

15 Panagiotou M, Peacock AJ, Johnson MK. Respiratory and limb muscle dysfunction in pulmonary arterial hypertension: a role for exercise training? Pulm Circ 2015; 5: 424-434.

16 Guazzi M, Adams V, Conraads V, et al. EACPR/AHA Joint Scientific Statement. Clinical recommendations for cardiopulmonary exercise testing data assessment in specific patient populations. Eur Heart $J$ 2012; 33: 2917-2927.

17 Sun XG, Hansen JE, Oudiz RJ, et al. Exercise pathophysiology in patients with primary pulmonary hypertension. Circulation 2001; 104: 429-435.

18 Arena R, Lavie CJ, Milani RV, et al. Cardiopulmonary exercise testing in patients with pulmonary arterial hypertension: an evidence-based review. J Heart Lung Transplant 2010; 29: 159-173.

19 Weatherald J, Farina S, Bruno N, et al. Cardiopulmonary exercise testing in pulmonary hypertension. Ann Am Thorac Soc 2017; 14: Suppl. 1, S84-S92.

20 Sun XG, Hansen JE, Oudiz RJ, et al. Gas exchange detection of exercise-induced right-to-left shunt in patients with primary pulmonary hypertension. Circulation 2002; 105: 54-60.

21 Bossone $\mathrm{E}$, D’Andrea A, D'Alto $\mathrm{M}$, et al. Echocardiography in pulmonary arterial hypertension: from diagnosis to prognosis. J Am Soc Echocardiogr 2013; 26: 1-14.

22 Markowitz DH, Systrom DM. Diagnosis of pulmonary vascular limit to exercise by cardiopulmonary exercise testing. J Heart Lung Transplant 2004; 23: 88-95.

23 Oldham WM, Oliveira RKF, Wang RS, et al. Network analysis to risk stratify patients with exercise intolerance. Circ Res 2018; 122: 864-876.

24 Deboeck G, Niset G, Vachiery JL, et al. Physiological response to the six-minute walk test in pulmonary arterial hypertension. Eur Respir J 2005; 26: 667-672.

25 Mainguy V, Provencher S, Maltais F, et al. Assessment of daily life physical activities in pulmonary arterial hypertension. PLoS One 2011; 6: e27993.

26 Pugh ME, Buchowski MS, Robbins IM, et al. Physical activity limitation as measured by accelerometry in pulmonary arterial hypertension. Chest 2012; 142: 1391-1398. 
Wensel R, Opitz CF, Anker SD, et al. Assessment of survival in patients with primary pulmonary hypertension: importance of cardiopulmonary exercise testing. Circulation 2002; 106: 319-324.

Miyamoto S, Nagaya N, Satoh T, et al. Clinical correlates and prognostic significance of six-minute walk test in patients with primary pulmonary hypertension. Comparison with cardiopulmonary exercise testing. Am J Respir Crit Care Med 2000; 161: 487-492.

Benza RL, Gomberg-Maitland M, Elliott CG, et al. Predicting survival in patients with pulmonary arterial hypertension: the REVEAL Risk Score Calculator 2.0 and comparison with ESC/ERS-based risk assessment strategies. Chest 2019; 156: 323-337.

Hoeper MM, Kramer T, Pan Z, et al. Mortality in pulmonary arterial hypertension: prediction by the 2015 European pulmonary hypertension guidelines risk stratification model. Eur Respir J 2017; 50: 1700740.

Maron BA, Galie N. Diagnosis, treatment, and clinical management of pulmonary arterial hypertension in the contemporary era: a review. JAMA Cardiol 2016; 1: 1056-1065.

Groepenhoff H, Vonk-Noordegraaf A, Boonstra A, et al. Exercise testing to estimate survival in pulmonary hypertension. Med Sci Sports Exerc 2008; 40: 1725-1732.

Frost AE, Langleben D, Oudiz R, et al. The 6-min walk test (6MW) as an efficacy endpoint in pulmonary arterial hypertension clinical trials: demonstration of a ceiling effect. Vascul Pharmacol 2005; 43: 36-39.

Degano B, Sitbon O, Savale L, et al. Characterization of pulmonary arterial hypertension patients walking more than $450 \mathrm{~m}$ in $6 \mathrm{~min}$ at diagnosis. Chest 2010; 137: 1297-1303.

Lee WT, Peacock AJ, Johnson MK. The role of per cent predicted 6-min walk distance in pulmonary arterial hypertension. Eur Respir J 2010; 36: 1294-1301.

Casanova C, Celli BR, Barria P, et al. The 6-min walk distance in healthy subjects: reference standards from seven countries. Eur Respir J 2011; 37: 150-156.

Costa GOS, Ramos RP, Oliveira RKF, et al. Prognostic value of six-minute walk distance at a South American pulmonary hypertension referral center. Pulm Circ 2020; 10: 2045894019888422.

Galie N, Manes A, Negro L, et al. A meta-analysis of randomized controlled trials in pulmonary arterial hypertension. Eur Heart J 2009; 30: 394-403.

Mathai SC, Puhan MA, Lam D, et al. The minimal important difference in the 6-minute walk test for patients with pulmonary arterial hypertension. Am J Respir Crit Care Med 2012; 186: 428-433.

Lajoie AC, Lauziere G, Lega JC, et al. Combination therapy versus monotherapy for pulmonary arterial hypertension: a meta-analysis. Lancet Respir Med 2016; 4: 291-305.

Gabler NB, French B, Strom BL, et al. Validation of 6-minute walk distance as a surrogate end point in pulmonary arterial hypertension trials. Circulation 2012; 126: 349-356.

McLaughlin VV, Badesch DB, Delcroix M, et al. End points and clinical trial design in pulmonary arterial hypertension. J Am Coll Cardiol 2009; 54: Suppl. 1, S97-S107.

Barst RJ, Langleben D, Frost A, et al. Sitaxsentan therapy for pulmonary arterial hypertension. Am J Respir Crit Care Med 2004; 169: 441-447.

Barst RJ, McGoon M, McLaughlin V, et al. Beraprost therapy for pulmonary arterial hypertension. J Am Coll Cardiol 2003; 41: 2119-2125.

Savarese G, Musella F, D’Amore C, et al. Haemodynamics, exercise capacity and clinical events in pulmonary arterial hypertension. Eur Respir J 2013; 42: 414-424.

Oga T, Nishimura K, Tsukino M, et al. The effects of oxitropium bromide on exercise performance in patients with stable chronic obstructive pulmonary disease. A comparison of three different exercise tests. Am $J$ Respir Crit Care Med 2000; 161: 1897-1901.

4 Deboeck G, Scoditti C, Huez S, et al. Exercise testing to predict outcome in idiopathic versus associated pulmonary arterial hypertension. Eur Respir J 2012; 40: 1410-1419.

Minai OA, Gudavalli R, Mummadi S, et al. Heart rate recovery predicts clinical worsening in patients with pulmonary arterial hypertension. Am J Respir Crit Care Med 2012; 185: 400-408.

Humbert M, Guignabert C, Bonnet S, et al. Pathology and pathobiology of pulmonary hypertension: state of the art and research perspectives. Eur Respir J 2019; 53: 1801887.

Ting $\mathrm{H}$, Sun $\mathrm{XG}$, Chuang $\mathrm{ML}$, et al. A noninvasive assessment of pulmonary perfusion abnormality in patients with primary pulmonary hypertension. Chest 2001; 119: 824-832.

Agostoni P, Farina S, Apostolo A, et al. Inside ventilatory regulation in pulmonary hypertension: several hidden data are still undiscovered. Eur J Prev Cardiol 2014; 21: 268-271.

Farina S, Correale M, Bruno $\mathrm{N}$, et al. The role of cardiopulmonary exercise tests in pulmonary arterial hypertension. Eur Respir Rev 2018; 27: 170134.

3 Yasunobu Y, Oudiz RJ, Sun XG, et al. End-tidal PCO2 abnormality and exercise limitation in patients with primary pulmonary hypertension. Chest 2005; 127: 1637-1646.

Hoeper MM, Pletz MW, Golpon H, et al. Prognostic value of blood gas analyses in patients with idiopathic pulmonary arterial hypertension. Eur Respir J 2007; 29: 944-950.

Farina S, Bruno N, Agalbato C, et al. Physiological insights of exercise hyperventilation in arterial and chronic thromboembolic pulmonary hypertension. Int J Cardiol 2018; 259: 178-182. 
Deboeck G, Niset G, Lamotte M, et al. Exercise testing in pulmonary arterial hypertension and in chronic heart failure. Eur Respir J 2004; 23: 747-751.

Corra U, Giordano A, Bosimini E, et al. Oscillatory ventilation during exercise in patients with chronic heart failure: clinical correlates and prognostic implications. Chest 2002; 121: 1572-1580.

Guazzi M, Raimondo R, Vicenzi M, et al. Exercise oscillatory ventilation may predict sudden cardiac death in heart failure patients. J Am Coll Cardiol 2007; 50: 299-308.

Murphy RM, Shah RV, Malhotra R, et al. Exercise oscillatory ventilation in systolic heart failure: an indicator of impaired hemodynamic response to exercise. Circulation 2011; 124: 1442-1451.

Ponikowski P, Chua TP, Anker SD, et al. Peripheral chemoreceptor hypersensitivity: an ominous sign in patients with chronic heart failure. Circulation 2001; 104: 544-549.

Ponikowski P, Chua TP, Piepoli M, et al. Augmented peripheral chemosensitivity as a potential input to baroreflex impairment and autonomic imbalance in chronic heart failure. Circulation 1997; 96: 2586-2594.

Vicenzi M, Deboeck G, Faoro V, et al. Exercise oscillatory ventilation in heart failure and in pulmonary arterial hypertension. Int J Cardiol 2016; 202: 736-740.

Breda AP, Pereira de Albuquerque AL, Jardim C, et al. Skeletal muscle abnormalities in pulmonary arterial hypertension. PLoS One 2014; 9: e114101.

Kabitz HJ, Schwoerer A, Bremer HC, et al. Impairment of respiratory muscle function in pulmonary hypertension. Clin Sci (Lond) 2008; 114: 165-171.

Meyer FJ, Lossnitzer D, Kristen AV, et al. Respiratory muscle dysfunction in idiopathic pulmonary arterial hypertension. Eur Respir J 2005; 25: 125-130.

Potus F, Malenfant S, Graydon C, et al. Impaired angiogenesis and peripheral muscle microcirculation loss contribute to exercise intolerance in pulmonary arterial hypertension. Am J Respir Crit Care Med 2014; 190: 318-328.

de Man FS, van Hees HW, Handoko ML, et al. Diaphragm muscle fiber weakness in pulmonary hypertension. Am J Respir Crit Care Med 2011; 183: 1411-1418.

Manders E, de Man FS, Handoko ML, et al. Diaphragm weakness in pulmonary arterial hypertension: role of sarcomeric dysfunction. Am J Physiol Lung Cell Mol Physiol 2012; 303: L1070-L1078.

Boucly A, Morelot-Panzini C, Garcia G, et al. Intensity and quality of exertional dyspnoea in patients with stable pulmonary hypertension. Eur Respir J 2020; 55: 1802108.

Laveneziana P, Garcia G, Joureau B, et al. Dynamic respiratory mechanics and exertional dyspnoea in pulmonary arterial hypertension. Eur Respir J 2013; 41: 578-587.

van Wolferen SA, Marcus JT, Boonstra A, et al. Prognostic value of right ventricular mass, volume, and function in idiopathic pulmonary arterial hypertension. Eur Heart J 2007; 28: 1250-1257.

MacNee W. Pathophysiology of cor pulmonale in chronic obstructive pulmonary disease. Part One. Am J Respir Crit Care Med 1994; 150: 833-852.

Provencher S, Herve P, Sitbon 0 , et al. Changes in exercise haemodynamics during treatment in pulmonary arterial hypertension. Eur Respir J 2008; 32: 393-398.

Brown SB, Raina A, Katz D, et al. Longitudinal shortening accounts for the majority of right ventricular contraction and improves after pulmonary vasodilator therapy in normal subjects and patients with pulmonary arterial hypertension. Chest 2011; 140: 27-33.

Sanz J, Sanchez-Quintana D, Bossone E, et al. Anatomy, function, and dysfunction of the right ventricle: JACC state-of-the-art review. J Am Coll Cardiol 2019; 73: 1463-1482.

Vonk Noordegraaf A, Chin KM, Haddad F, et al. Pathophysiology of the right ventricle and of the pulmonary circulation in pulmonary hypertension: an update. Eur Respir J 2019; 53: 1801900.

Meloche J, Lampron MC, Nadeau V, et al. Implication of inflammation and epigenetic readers in coronary artery remodeling in patients with pulmonary arterial hypertension. Arterioscler Thromb Vasc Biol 2017; 37: 1513-1523.

Potus F, Ruffenach G, Dahou A, et al. Downregulation of microRNA-126 contributes to the failing right ventricle in pulmonary arterial hypertension. Circulation 2015; 132: 932-943.

Rain S, Handoko ML, Trip P, et al. Right ventricular diastolic impairment in patients with pulmonary arterial hypertension. Circulation 2013; 128: 2016-2025. 2011-2010.

Piao L, Fang YH, Cadete VJ, et al. The inhibition of pyruvate dehydrogenase kinase improves impaired cardiac function and electrical remodeling in two models of right ventricular hypertrophy: resuscitating the hibernating right ventricle. J Mol Med (Berl) 2010; 88: 47-60.

Borlaug BA, Reddy YNV. The role of the pericardium in heart failure: implications for pathophysiology and treatment. JACC Heart Fail 2019; 7: 574-585.

Kasner M, Westermann D, Steendijk $\mathrm{P}$, et al. Left ventricular dysfunction induced by nonsevere idiopathic pulmonary arterial hypertension: a pressure-volume relationship study. Am J Respir Crit Care Med 2012; 186: 181-189.

Manders E, Bogaard HJ, Handoko ML, et al. Contractile dysfunction of left ventricular cardiomyocytes in patients with pulmonary arterial hypertension. J Am Coll Cardiol 2014; 64: 28-37. 
Gorter TM, Obokata M, Reddy YNV, et al. Exercise unmasks distinct pathophysiologic features in heart failure with preserved ejection fraction and pulmonary vascular disease. Eur Heart J 2018; 39: 2825-2835.

Blumberg FC, Arzt M, Lange T, et al. Impact of right ventricular reserve on exercise capacity and survival in patients with pulmonary hypertension. Eur J Heart Fail 2013; 15: 771-775.

Chaouat A, Sitbon O, Mercy M, et al. Prognostic value of exercise pulmonary haemodynamics in pulmonary arterial hypertension. Eur Respir J 2014; 44: 704-713.

Jaijee S, Quinlan M, Tokarczuk P, et al. Exercise cardiac MRI unmasks right ventricular dysfunction in acute hypoxia and chronic pulmonary arterial hypertension. Am J Physiol Heart Circ Physiol 2018; 315: H950-H957.

Lin AC, Strugnell WE, Seale $\mathrm{H}$, et al. Exercise cardiac MRI-derived right ventriculo-arterial coupling ratio detects early right ventricular maladaptation in PAH. Eur Respir J 2016; 48: 1797-1800.

Provencher S, Chemla D, Herve P, et al. Heart rate responses during the 6-minute walk test in pulmonary arterial hypertension. Eur Respir J 2006; 27: 114-120.

Spruijt OA, de Man FS, Groepenhoff $\mathrm{H}$, et al. The effects of exercise on right ventricular contractility and right ventricular-arterial coupling in pulmonary hypertension. Am J Respir Crit Care Med 2015; 191: 1050-1057.

Badagliacca R, Papa S, Valli G, et al. Right ventricular dyssynchrony and exercise capacity in idiopathic pulmonary arterial hypertension. Eur Respir J 2017; 49: 1601419.

Hsu S, Houston BA, Tampakakis E, et al. Right ventricular functional reserve in pulmonary arteria hypertension. Circulation 2016; 133: 2413-2422.

Groepenhoff $\mathrm{H}$, Westerhof $\mathrm{N}$, Jacobs W, et al. Exercise stroke volume and heart rate response differ in right and left heart failure. Eur J Heart Fail 2010; 12: 716-720.

Andersen MJ, Nishimura RA, Borlaug BA. The hemodynamic basis of exercise intolerance in tricuspid regurgitation. Circ Heart Fail 2014; 7: 911-917.

Willie CK, Tzeng YC, Fisher JA, et al. Integrative regulation of human brain blood flow. J Physiol 2014; 592: 841-859.

Rasmussen P, Nielsen J, Overgaard M, et al. Reduced muscle activation during exercise related to brain oxygenation and metabolism in humans. J Physiol 2010; 588: 1985-1995.

Smith KJ, MacLeod D, Willie CK, et al. Influence of high altitude on cerebral blood flow and fuel utilization during exercise and recovery. J Physiol 2014; 592: 5507-5527.

Fu TC, Wang CH, Hsu CC, et al. Suppression of cerebral hemodynamics is associated with reduced functional capacity in patients with heart failure. Am J Physiol Heart Circ Physiol 2011; 300: H1545-H1555.

Brassard P, Gustafsson F. Exercise intolerance in heart failure: did we forget the brain? Can J Cardiol 2016; 32: 475-484.

Smith KJ, Suarez IM, Scheer A, et al. Cerebral blood flow during exercise in heart failure: effect of ventricular assist devices. Med Sci Sports Exerc 2019; 51: 1372-1379.

Koike A, Itoh H, Oohara R, et al. Cerebral oxygenation during exercise in cardiac patients. Chest 2004; 125 182-190.

Caldas JR, Panerai RB, Haunton VJ, et al. Cerebral blood flow autoregulation in ischemic heart failure. Am J Physiol Regul Integr Comp Physiol 2017; 312: R108-R113.

Caldas JR, Panerai RB, Salinet AM, et al. Dynamic cerebral autoregulation is impaired during submaximal isometric handgrip in patients with heart failure. Am J Physiol Heart Circ Physiol 2018; 315: H254-H261.

Erkelens CD, van der Wal HH, de Jong BM, et al. Dynamics of cerebral blood flow in patients with mild non-ischaemic heart failure. Eur J Heart Fail 2017; 19: 261-268.

Treptow E, Oliveira MF, Soares A, et al. Cerebral microvascular blood flow and $\mathrm{CO}_{2}$ reactivity in pulmonary arterial hypertension. Respir Physiol Neurobiol 2016; 233: 60-65.

Muller-Mottet S, Hildenbrand FF, Keusch S, et al. Effects of exercise and vasodilators on cerebral tissue oxygenation in pulmonary hypertension. Lung 2015; 193: 113-120.

Mar PL, Nwazue V, Black BK, et al. Valsalva maneuver in pulmonary arterial hypertension: susceptibility to syncope and autonomic dysfunction. Chest 2016; 149: 1252-1260.

Malenfant S, Brassard P, Paquette M, et al. Continuous reduction in cerebral oxygenation during endurance exercise in patients with pulmonary arterial hypertension. Physiol Rep 2020; 8: e14389.

Ulrich S, Hasler ED, Saxer S, et al. Effect of breathing oxygen-enriched air on exercise performance in patients with precapillary pulmonary hypertension: randomized, sham-controlled cross-over trial. Eur Heart J 2017; 38: 1159-1168.

0 Bauer R, Dehnert C, Schoene P, et al. Skeletal muscle dysfunction in patients with idiopathic pulmonary arterial hypertension. Respir Med 2007; 101: 2366-2369.

Manders E, Ruiter G, Bogaard HJ, et al. Quadriceps muscle fibre dysfunction in patients with pulmonary arterial hypertension. Eur Respir J 2015; 45: 1737-1740.

2 Batt J, Ahmed SS, Correa J, et al. Skeletal muscle dysfunction in idiopathic pulmonary arterial hypertension. Am J Respir Cell Mol Biol 2014; 50: 74-86.

Garfield BE, Crosby A, Shao D, et al. Growth/differentiation factor 15 causes TGFbeta-activated kinase 1-dependent muscle atrophy in pulmonary arterial hypertension. Thorax 2019; 74: 164-176. 
114 Moreira-Goncalves D, Padrao AI, Ferreira R, et al. Signaling pathways underlying skeletal muscle wasting in experimental pulmonary arterial hypertension. Biochim Biophys Acta 2015; 1852: 2722-2731.

115 Yndestad A, Larsen KO, Oie E, et al. Elevated levels of activin A in clinical and experimental pulmonary hypertension. J Appl Physiol (1985) 2009; 106: 1356-1364.

116 Rhodes CJ, Ghataorhe P, Wharton J, et al. Plasma metabolomics implicates modified transfer RNAs and altered bioenergetics in the outcomes of pulmonary arterial hypertension. Circulation 2017; 135: 460-475.

117 Fukawa T, Yan-Jiang BC, Min-Wen JC, et al. Excessive fatty acid oxidation induces muscle atrophy in cancer cachexia. Nat Med 2016; 22: 666-671.

118 Vinke P, Bowen TS, Boekschoten MV, et al. Anti-inflammatory nutrition with high protein attenuates cardiac and skeletal muscle alterations in a pulmonary arterial hypertension model. Sci Rep 2019; 9: 10160.

119 Malenfant S, Potus F, Fournier F, et al. Skeletal muscle proteomic signature and metabolic impairment in pulmonary hypertension. J Mol Med (Berl) 2015; 93: 573-584.

120 Wust RC, Myers DS, Stones R, et al. Regional skeletal muscle remodeling and mitochondrial dysfunction in right ventricular heart failure. Am J Physiol Heart Circ Physiol 2012; 302: H402-H411.

121 Zurlo F, Larson K, Bogardus C, et al. Skeletal muscle metabolism is a major determinant of resting energy expenditure. J Clin Invest 1990; 86: 1423-1427.

122 Armstrong RB, Delp MD, Goljan EF, et al. Distribution of blood flow in muscles of miniature swine during exercise. J Appl Physiol (1985) 1987; 62: 1285-1298.

123 Manohar M. Blood flow to the respiratory and limb muscles and to abdominal organs during maximal exertion in ponies. J Physiol 1986; 377: 25-35.

124 Laughlin MH, Klabunde RE, Delp MD, et al. Effects of dipyridamole on muscle blood flow in exercising miniature swine. Am J Physiol 1989; 257: H1507-H1515.

125 Knight DR, Poole DC, Schaffartzik W, et al. Relationship between body and leg VO2 during maximal cycle ergometry. J Appl Physiol (1985) 1992; 73: 1114-1121.

126 Aaron EA, Seow KC, Johnson BD, et al. Oxygen cost of exercise hyperpnea: implications for performance. J Appl Physiol (1985) 1992; 72: 1818-1825.

127 Tolle J, Waxman A, Systrom D. Impaired systemic oxygen extraction at maximum exercise in pulmonary hypertension. Med Sci Sports Exerc 2008; 40: 3-8.

128 Levine $\mathrm{BD} . \mathrm{VO}_{2}$ max: what do we know, and what do we still need to know? J Physiol 2008; 586: 25-34.

129 Panagiotou M, Johnson MK, Louvaris Z, et al. A study of clinical and physiological relations of daily physical activity in precapillary pulmonary hypertension. J Appl Physiol (1985) 2017; 123: 851-859.

130 Roca J, Agusti AG, Alonso A, et al. Effects of training on muscle $\mathrm{O}_{2}$ transport at $\mathrm{VO}_{2}$ max. J Appl Physiol (1985) 1992; 73: 1067-1076.

131 Katz SD, Balidemaj K, Homma S, et al. Acute type 5 phosphodiesterase inhibition with sildenafil enhances flow-mediated vasodilation in patients with chronic heart failure. J Am Coll Cardiol 2000; 36: 845-851.

132 Wray DW, Nishiyama SK, Donato AJ, et al. Endothelin-1-mediated vasoconstriction at rest and during dynamic exercise in healthy humans. Am J Physiol Heart Circ Physiol 2007; 293: H2550-H2556.

133 Thijssen DH, Ellenkamp R, Kooijman M, et al. A causal role for endothelin-1 in the vascular adaptation to skeletal muscle deconditioning in spinal cord injury. Arterioscler Thromb Vasc Biol 2007; 27: 325-331.

134 Strachan FE, Newby DE, Sciberras DG, et al. Repeatability of local forearm vasoconstriction to endothelin-1 measured by venous occlusion plethysmography. Br J Clin Pharmacol 2002; 54: 386-394.

135 Spratt JC, Goddard J, Patel N, et al. Systemic ETA receptor antagonism with BQ-123 blocks ET-1 induced forearm vasoconstriction and decreases peripheral vascular resistance in healthy men. Br J Pharmacol 2001; 134: 648-654.

136 Donato AJ, Lesniewski LA, Delp MD. The effects of aging and exercise training on endothelin-1 vasoconstrictor responses in rat skeletal muscle arterioles. Cardiovasc Res 2005; 66: 393-401.

137 Pringle JS, Doust JH, Carter H, et al. Oxygen uptake kinetics during moderate, heavy and severe intensity "submaximal" exercise in humans: the influence of muscle fibre type and capillarisation. Eur J Appl Physiol 2003; 89: 289-300.

138 Boushel R, Langberg $\mathrm{H}$, Gemmer C, et al. Combined inhibition of nitric oxide and prostaglandins reduces human skeletal muscle blood flow during exercise. J Physiol 2002; 543: 691-698.

139 Schrage WG, Joyner MJ, Dinenno FA. Local inhibition of nitric oxide and prostaglandins independently reduces forearm exercise hyperaemia in humans. J Physiol 2004; 557: 599-611.

140 Nadeau V, Potus F, Boucherat O, et al. Dual ETA/ETB blockade with macitentan improves both vascular remodeling and angiogenesis in pulmonary arterial hypertension. Pulm Circ 2018; 8: 2045893217741429.

141 Ryan JJ, Archer SL. The right ventricle in pulmonary arterial hypertension: disorders of metabolism, angiogenesis and adrenergic signaling in right ventricular failure. Circ Res 2014; 115: 176-188.

142 Enache I, Charles AL, Bouitbir J, et al. Skeletal muscle mitochondrial dysfunction precedes right ventricular impairment in experimental pulmonary hypertension. Mol Cell Biochem 2013; 373: 161-170.

143 Boucherat O, Peterlini T, Bourgeois A, et al. Mitochondrial HSP90 accumulation promotes vascular remodeling in pulmonary arterial hypertension. Am J Respir Crit Care Med 2018; 198: 90-103. 
144 Sithamparanathan S, Rocha MC, Parikh JD, et al. Skeletal muscle mitochondrial oxidative phosphorylation function in idiopathic pulmonary arterial hypertension: in vivo and in vitro study. Pulm Circ 2018; 8: 2045894018768290.

145 McCullough DJ, Kue N, Mancini T, et al. Endurance exercise training in pulmonary hypertension increases skeletal muscle electron transport chain supercomplex assembly. Pulm Circ 2020; 10: 2045894020925762.

146 Handoko ML, de Man FS, Happe CM, et al. Opposite effects of training in rats with stable and progressive pulmonary hypertension. Circulation 2009; 120: 42-49.

147 Mereles D, Ehlken N, Kreuscher S, et al. Exercise and respiratory training improve exercise capacity and quality of life in patients with severe chronic pulmonary hypertension. Circulation 2006; 114: 1482-1489.

148 Mainguy V, Maltais F, Saey D, et al. Effects of a rehabilitation program on skeletal muscle function in idiopathic pulmonary arterial hypertension. J Cardiopulm Rehabil Prev 2010; 30: 319-323.

149 Chan L, Chin LMK, Kennedy M, et al. Benefits of intensive treadmill exercise training on cardiorespiratory function and quality of life in patients with pulmonary hypertension. Chest 2013; 143: 333-343.

150 Grunig E, Maier F, Ehlken N, et al. Exercise training in pulmonary arterial hypertension associated with connective tissue diseases. Arthritis Res Ther 2012; 14: R148.

151 Becker-Grunig $\mathrm{T}$, Klose $\mathrm{H}$, Ehlken $\mathrm{N}$, et al. Efficacy of exercise training in pulmonary arterial hypertension associated with congenital heart disease. Int J Cardiol 2013; 168: 375-381.

152 Nagel C, Prange F, Guth S, et al. Exercise training improves exercise capacity and quality of life in patients with inoperable or residual chronic thromboembolic pulmonary hypertension. PLoS One 2012; 7: e41603.

153 Grunig E, Ehlken N, Ghofrani A, et al. Effect of exercise and respiratory training on clinical progression and survival in patients with severe chronic pulmonary hypertension. Respiration 2011; 81: 394-401.

154 Kabitz HJ, Bremer HC, Schwoerer A, et al. The combination of exercise and respiratory training improves respiratory muscle function in pulmonary hypertension. Lung 2014; 192: 321-328.

155 Pandey A, Garg S, Khunger M, et al. Efficacy and safety of exercise training in chronic pulmonary hypertension: systematic review and meta-analysis. Circ Heart Fail 2015; 8: 1032-1043.

156 Ehlken $\mathrm{N}$, Lichtblau $\mathrm{M}$, Klose $\mathrm{H}$, et al. Exercise training improves peak oxygen consumption and haemodynamics in patients with severe pulmonary arterial hypertension and inoperable chronic thromboembolic pulmonary hypertension: a prospective, randomized, controlled trial. Eur Heart J 2016; 37: 35-44.

157 Richter MJ, Grimminger J, Kruger B, et al. Effects of exercise training on pulmonary hemodynamics, functional capacity and inflammation in pulmonary hypertension. Pulm Circ 2017; 7: 20-37.

158 Tickle PG, Hendrickse PW, Degens $\mathrm{H}$, et al. Impaired skeletal muscle performance as a consequence of random functional capillary rarefaction can be restored with overload-dependent angiogenesis. J Physiol 2020; 598: 1187-1203.

159 Reeves JT, Linehan JH, Stenmark KR. Distensibility of the normal human lung circulation during exercise. Am J Physiol Lung Cell Mol Physiol 2005; 288: L419-L425.

160 La Gerche A, Maclsaac Al, Burns AT, et al. Pulmonary transit of agitated contrast is associated with enhanced pulmonary vascular reserve and right ventricular function during exercise. J Appl Physiol (1985) 2010; 109: 1307-1317.

161 Badesch DB, Champion HC, Sanchez MA, et al. Diagnosis and assessment of pulmonary arterial hypertension. J Am Coll Cardiol 2009; 54: Suppl. 1, S55-S66.

162 Kovacs G, Berghold A, Scheidl S, et al. Pulmonary arterial pressure during rest and exercise in healthy subjects: a systematic review. Eur Respir J 2009; 34: 888-894.

163 Naeije R, Vanderpool R, Dhakal BP, et al. Exercise-induced pulmonary hypertension: physiological basis and methodological concerns. Am J Respir Crit Care Med 2013; 187: 576-583.

164 Herve P, Lau EM, Sitbon O, et al. Criteria for diagnosis of exercise pulmonary hypertension. Eur Respir J 2015; 46: 728-737.

165 Ho JE, Zern EK, Lau ES, et al. Exercise pulmonary hypertension predicts clinical outcomes in patients with dyspnea on effort. J Am Coll Cardiol 2020; 75: 17-26.

166 Segrera SA, Lawler L, Opotowsky AR, et al. Open label study of ambrisentan in patients with exercise pulmonary hypertension. Pulm Circ 2017; 7: 531-538.

167 Kennedy TP, Michael JR, Huang CK, et al. Nifedipine inhibits hypoxic pulmonary vasoconstriction during rest and exercise in patients with chronic obstructive pulmonary disease. A controlled double-blind study. Am Rev Respir Dis 1984; 129: 544-551.

168 Archer SL, Mike D, Crow J, et al. A placebo-controlled trial of prostacyclin in acute respiratory failure in COPD. Chest 1996; 109: 750-755.

169 Lau EMT, Chemla D, Godinas L, et al. Loss of vascular distensibility during exercise is an early hemodynamic marker of pulmonary vascular disease. Chest 2016; 149: 353-361.

170 Lalande S, Yerly P, Faoro V, et al. Pulmonary vascular distensibility predicts aerobic capacity in healthy individuals. J Physiol 2012; 590: 4279-4288.

171 Singh I, Oliveira RKF, Naeije R, et al. Pulmonary vascular distensibility and early pulmonary vascular remodeling in pulmonary hypertension. Chest 2019; 156: 724-732. 
172 Malhotra R, Dhakal BP, Eisman AS, et al. Pulmonary vascular distensibility predicts pulmonary hypertension severity, exercise capacity, and survival in heart failure. Circ Heart Fail 2016; 9: e003011.

173 Kovacs G, Herve P, Barbera JA, et al. An official European Respiratory Society statement: pulmonary haemodynamics during exercise. Eur Respir J 2017; 50: 1700578.

174 Kovacs $\mathrm{G}$, Herve P, Olschewski $\mathrm{H}$, et al. The pulmonary haemodynamics during exercise-research network (PEX-NET) ERS Clinical Research Collaboration: investigating the prognostic relevance of exercise haemodynamics. Eur Respir J 2019; 53: 1900458.

175 Poole DC, Behnke BJ, Musch TI. The role of vascular function on exercise capacity in health and disease. J Physiol 2020; in press.

176 Poole DC, Richardson RS, Haykowsky MJ, et al. Exercise limitations in heart failure with reduced and preserved ejection fraction. J Appl Physiol (1985) 2018; 124: 208-224.

177 Harms CA, Babcock MA, McClaran SR, et al. Respiratory muscle work compromises leg blood flow during maximal exercise. J Appl Physiol (1985) 1997; 82: 1573-1583.

178 Dempsey JA, Miller JD, Romer L, et al. Exercise-induced respiratory muscle work: effects on blood flow, fatigue and performance. Adv Exp Med Biol 2008; 605: 209-212.

179 Miyazaki $\mathrm{A}$, Adachi $\mathrm{H}$, Oshima $\mathrm{S}$, et al. Blood flow redistribution during exercise contributes to exercise tolerance in patients with chronic heart failure. Circ $J$ 2007; 71: 465-470.

180 Dempsey JA, Romer L, Rodman J, et al. Consequences of exercise-induced respiratory muscle work. Respir Physiol Neurobiol 2006; 151: 242-250.

181 Amann M, Regan MS, Kobitary M, et al. Impact of pulmonary system limitations on locomotor muscle fatigue in patients with COPD. Am J Physiol Regul Integr Comp Physiol 2010; 299: R314-R324.

182 Spiekerkoetter E, Fabel H, Hoeper MM. Effects of inhaled salbutamol in primary pulmonary hypertension. Eur Respir J 2002; 20: 524-528.

183 Faria-Urbina M, Oliveira RKF, Segrera SA, et al. Impaired systemic oxygen extraction in treated exercise pulmonary hypertension: a new engine in an old car? Pulm Circ 2018; 8: 2045893218755325.

184 Cano I, Roca J, Wagner PD. Effects of lung ventilation-perfusion and muscle metabolism-perfusion heterogeneities on maximal $\mathrm{O} 2$ transport and utilization. J Physiol 2015; 593: 1841-1856.

185 Esposito F, Mathieu-Costello O, Shabetai R, et al. Limited maximal exercise capacity in patients with chronic heart failure: partitioning the contributors. J Am Coll Cardiol 2010; 55: 1945-1954.

186 Esposito F, Reese V, Shabetai R, et al. Isolated quadriceps training increases maximal exercise capacity in chronic heart failure: the role of skeletal muscle convective and diffusive oxygen transport. J Am Coll Cardiol 2011; 58: 1353-1362.

187 Esposito F, Mathieu-Costello O, Wagner PD, et al. Acute and chronic exercise in patients with heart failure with reduced ejection fraction: evidence of structural and functional plasticity and intact angiogenic signalling in skeletal muscle. J Physiol 2018; 596: 5149-5161.

188 Houstis NE, Eisman AS, Pappagianopoulos PP, et al. Exercise intolerance in heart failure with preserved ejection fraction: diagnosing and ranking its causes using personalized $\mathrm{O}_{2}$ pathway analysis. Circulation 2018; 137: 148-161.

189 Dhakal BP, Malhotra R, Murphy RM, et al. Mechanisms of exercise intolerance in heart failure with preserved ejection fraction: the role of abnormal peripheral oxygen extraction. Circ Heart Fail 2015; 8: 286-294.

190 Broxterman RM, Hoff J, Wagner PD, et al. Determinants of the diminished exercise capacity in patients with chronic obstructive pulmonary disease: looking beyond the lungs. J Physiol 2020; 598: 599-610.

191 Williamson JW, Fadel PJ, Mitchell JH. New insights into central cardiovascular control during exercise in humans: a central command update. Exp Physiol 2006; 91: 51-58.

192 Ponikowski PP, Chua TP, Francis DP, et al. Muscle ergoreceptor overactivity reflects deterioration in clinical status and cardiorespiratory reflex control in chronic heart failure. Circulation 2001; 104: 2324-2330.

193 Piepoli MF, Kaczmarek A, Francis DP, et al. Reduced peripheral skeletal muscle mass and abnormal reflex physiology in chronic heart failure. Circulation 2006; 114: 126-134.

194 Amann M, Blain GM, Proctor LT, et al. Group III and IV muscle afferents contribute to ventilatory and cardiovascular response to rhythmic exercise in humans. J Appl Physiol (1985) 2010; 109: 966-976.

195 Amann M, Proctor LT, Sebranek JJ, et al. Opioid-mediated muscle afferents inhibit central motor drive and limit peripheral muscle fatigue development in humans. J Physiol 2009; 587: 271-283.

196 Amann M, Blain GM, Proctor LT, et al. Implications of group III and IV muscle afferents for high-intensity endurance exercise performance in humans. J Physiol 2011; 589: Pt. 21, 5299-5309.

197 Broxterman RM, Hureau TJ, Layec G, et al. Influence of group III/IV muscle afferents on small muscle mass exercise performance: a bioenergetics perspective. J Physiol 2018; 596: 2301-2314.

198 Gagnon P, Bussieres JS, Ribeiro F, et al. Influences of spinal anesthesia on exercise tolerance in patients with chronic obstructive pulmonary disease. Am J Respir Crit Care Med 2012; 186: 606-615. 